\title{
The living and the dead
}

\section{The Evolutionary Biology of Plants by Karl J. Niklas \\ University of Chicago Press: 1997. Pp. 449. \\ $\$ 65, \mathfrak{E} 51.95$ ( $h b k$ ); $\$ 19.95, \mathfrak{E} 15.95$ (pbk). \\ Bill Chaloner}

There is a cultural divide in the spectrum of scientists who study plant evolution. At one end are those interested in the record in the rocks of what happened to plants over geological time. They base their work in the field, searching for the remains of past plant life in boreholes, mines and quarries. And having investigated these remains in the laboratory, they then try to reconstruct the biology of the plants as they were in life and interpret the way in which these plants have changed down the ages.

At the other end of the spectrum are those who seek to understand not so much what happened as how it happened. Some tackle this at the molecular and cellular level, looking at the genetic basis of inheritance and the aberrations that produce evolutionary change. Others with similar objectives study living plants and plant populations to understand the evolutionary process in action.

Differences of perspective and academic background have kept the palaeobotanist and the evolutionary geneticist apart. Karl J. Niklas now makes an inspired attempt to bridge this gap. He takes us through the current perceptions of the workings of plant genetics and the diversity of adaptation produced by natural selection and then looks back at the fossil record. Finally, he has a good shot at trying to bring the two fields together. One of his stated aims in writing the book is to "give the living and the dead equal attention", and this he largely achieves.

Much of Niklas's scholarly review of the origin of life, the evidence from cell biology of the relationship between prokaryotes and eukaryotes, and the processes of inheritance, mutation and evolution have been well presented in sources elsewhere. These are intended to educate the palaeobotanists. The important contribution of this book is to present to the other side of the cultural divide the evidence of plant evolution that has come from studying fossil plants during the past two or three decades.

But this is much more than a broad-based overview of palaeobotany. Niklas brings to the story a diverting assembly of new dimensions, many of which he has contributed to palaeobotany by his own research. He explores with simple computer models how plant architecture, leaf shape and arrangement have moulded plant evolution, as plants struck compromises between these structures and various environmental constraints. These "walks on a

fitness landscape" (a phrase borrowed from Sewall Wright) bring us back, but with a new insight, into problems of size and form in plants that were being explored by F. O. Bower 70 years ago.

Niklas's own research has included such diverse items as explaining how the properties of plant tissues can help us to understand the mechanical designs of extinct plants with their very different patterns of development from any now living; how the shape of early wind-pollinated seeds contributed to their aerodynamic efficiency; and how the pattern of plant evolution works on different rules from the innovations and mass extinction of the animal kingdom.

He also offers interesting new perspectives on many old themes. Insect pollination, which lies at the heart of flowering plant biology, works only "because animals can recognise flowers belonging to the same

\section{Other books on plants}

\section{Diversity and Classification of Flowering Plants}

by Armen Takhtajan

Columbia University Press, $\$ 109, £ 76$

A new revision of the author's 1967 classification system based on "descriptive keys" for individual families.

\section{Mycorrhizal Symbiosis}

by S. E. Smith and D. J. Real

Academic, \$74.95, £65

Second edition of a work that first appeared in 1983, providing a comprehensive review of the symbiotic fungi that colonize plant roots.

\section{New Flora of the British Isles}

by Clive Stage

Cambridge University Press, $£ 28.95, \$ 85$ (pbk)

The second edition of this standard work now covers more than 4,500 taxa.

\section{Plant Ecology}

edited by Michael J. Crawley

Blackwell Science, £29.95 (pbk)

Second edition of this benchmark text, first published in 1986.

\section{Plant Functional Types: Their Relevance to Ecosystem Properties and Global Change}

edited by T. M. Smith, H. H. Shugart

and F. I. Woodward

Cambridge University Press, $£ 80, \$ 120$ (hbk);

$£ 29.95, \$ 44.95$ ( $p b k$ )

How to predict the effects of changing climate and carbon dioxide on plants at the global scale.

\section{Seed Production: Principles and} Practices

by Miller B. McDonald and Lawrence Copeland Chapman and Hall, $£ 49$

Reference text for students. species". In other words, insect pollination paid off because plants could teach insects to recognize different shapes and colours and so to adopt brand fidelity (a vital commercial principle — we pick the same package off the supermarket shelf each time). But it worked only because the insect brain could acquire a sound taxonomic training at the hands of the flowers.

In the final chapter, Niklas comes into his own in integrating the dead with the living, as he explores the molecular clock of plant evolution, the pattern of evolutionary tempo, and the mysteries of mass extinctions. Plant biologists have in one sense been waiting many years for this book, and yet perhaps its real importance lies in the fact they did not realize it was coming.

Bill Chaloner is in the Department of Geology, Royal Holloway, University of London, Egham, Surrey TW20 OEX, UK.

\section{Plant Genetic Conservation: The In Situ Approach}

edited by N. Maxted, B. V. Ford-Lloyd

and J. G. Hawkes

Chapman and Hall, £27.50 (pbk)

Includes methodologies and detailed discussion of on-farm and genetic-reserve conservation.

\section{Reaching for the Sun: How Plants Work}

by John King

Cambridge University Press, $£ 30, \$ 54.95$ ( $h b k$ ); $£ 9.95, \$ 16.95$ ( $p b k$ )

An accessible account for lay people.

\section{Practical Applications of Plant} Molecular Biology

by R. J. Henry

Chapman and Hall, £24.99 (pbk)

Introductory textbook and reference source.

\section{World Weeds: Natural Histories and Distribution}

by LeRoy Holm, Jerry Doll, Eric Holm, Juan Pancho and James Herberger

Wiley, $£ 150$

Comprehensive coverage of more than 100 species, with a bibliography of 3,000 references.

The Identification of Flowering Plant Families

by James Cullen

Cambridge University Press, £21.95, \$59.95 (hbk); $£ 12.95, \$ 35$ (pbk)

Fourth edition of a short, user-friendly guide aimed at botany and horticulture students.

\section{The Nature of Disease in Plants}

by Robert P. Scheffer

Cambridge University Press, £45, \$64.95

A natural history of some of the most damaging diseases worldwide. 